\title{
Building Stakeholder Relations Online: How Nonprofit Organizations Use Dialogic and Relational Maintenance Strategies on Facebook
}

Original scientific paper _ DOI 10.22522/cmr20170119 _ received on 1 April 2017 UDK 061.2:659.44 _ $00 \overline{4} .738$

\section{Nadine van Wissen}

World Animal Protection, The Netherlands. Email: NadineVanWissen@worldanimalprotection.nl

\section{Anke Wonneberger}

Department of Communication Science, University of Amsterdam, The Netherlands.

Email: A.Wonneberger@uva.nl (corresponding author)

\section{Abstract}

Although Facebook provides organizations with the opportunity to easily engage with stakeholders online, very little is known about the effectiveness of organizational communication strategies. This study examines how nonprofit organizations (NPOs) use Facebook to engage with stakeholders through stakeholder dialogic strategies and relational maintenance strategies with the goal of fostering stakeholder relationship growth and obtaining social legitimacy. Furthermore, this study takes full advantage of the research opportunities of social media by taking stakeholders' online responses to these organizational strategies into account. A manual content analysis of $\mathrm{N}=216$ posts and $\mathrm{N}=1,676$ comments of the Facebook profiles of ten international NPOs was conducted over one month in 2015. The results demonstrated that NPOs were more focused on technical and design aspects while true stakeholder dialogue and relational maintenance strategies were barely applied. Stakeholder dialogue positively influenced stakeholders' interest and engagement. Conversational human voice as a relational maintenance strategy positively affected stakeholders' engagement.

Keywords: stakeholder dialogue, relational maintenance strategies, conversational human voice, communicated relational commitment, social legitimacy, nonprofit organizations 


\section{Introduction}

Worldwide, millions of nonprofit organizations (NPOs) are active as social entrepreneurs, ranging from small to large sized NPOs and from local to internationally oriented actors. NPOs rely heavily on stakeholders to support them, for instance, by donating or volunteering (Balser, McClusky, 2005). Consequently, gaining and maintaining social legitimacy by meeting societal expectations is crucial (Ospina, Diaz, O'Sullivan, 2002). Building stakeholder relationships is essential for organizations if they want to identify these expectations and respond to them (Balser, McClusky, 2005). Multiple studies mention the importance for NPOs to apply two-way communication strategies and engage in ongoing dialogue to foster stakeholder relations (Ospina et al., 2002; Balser, McClusky, 2005). Due to their interactive, relational and global characteristics, social networking sites provide organizations with an important platform to apply such stakeholder dialogue and build relationships (Kent, Taylor, 1998). Research on NPOs' usage of social media is growing steadily. Some of these studies focus on whether NPOs use social media. This research shows that NPOs indeed see the importance of social media in identifying the needs and interests of stakeholders and building relationships through two-way communication (Greenleaf, 2016; Nah, Saxton, 2012). Stakeholders, in addition, seem to prefer organizational messages focusing on building relationships and communities through interactivity and dialogue above solely informative messages (Bellucci, Manetti, 2017; Saxton, Waters, 2014). Other studies look more in-depth how NPOs use social media specifically (Bortree, Seltzer, 2009; Waters et al., 2009). This research reveals that organizations concentrate more on transparency by providing information than on actually engaging with stakeholders.

These studies provide practical information on the organizational perception of social media, stakeholders' preferences of dialogical messages and how NPOs miss the opportunity to engage stakeholders in practice. However, little is known regarding the uses and effects of dialogue. While previous studies have, for instance, examined the effects of different message types on stakeholder engagement (Park, Reber, Chon, 2016; Huang, Lin, Saxton, 2016), relatively little is known in relation to how NPOs apply strategies for online stakeholder dialogue and, more importantly, about how these affect stakeholder engagement. The way organizations use the possibility of engaging stakeholders by posting status updates, remains an understudied topic, despite the fact that these posts are "the chief dynamic feature of social media sites" (Guo, Saxton, 2014, p. 61). 
In addition, research on how NPOs apply relational maintenance strategies on their social media platforms and how these affect stakeholder engagement is scarce. Relational maintenance strategies, such as conversational human voice or communicated relational commitment, can be used to build and maintain relationships with stakeholders online as they positively influence organization-stakeholder relationships (Kelleher, Miller, 2006).

The present study offers a more detailed understanding on how NPOs are engaging stakeholders and fostering relationship growth by analyzing the usage and effects of dialogic strategies and relational maintenance strategies. While previous studies have used social media metrics to operationalize stakeholder engagement (e.g., Guidry, Waters, Saxton, 2014), we take the content of stakeholder responses into account. Applying manual, quantitative content analysis on both Facebook profile- and message-level, this study contributes to the public relations literature as it extends the line of research to studying online stakeholder relationship building. We selected ten well-known international NPOs and analyzed a total of $N=216$ posts and $N=1,676$ comments published on their Facebook profiles during one month in 2015. The findings of this research have relevant practical implications since for NPOs it is important to know what is currently being done and how their use of online stakeholder dialogue strategies and relational maintenance strategies can be ameliorated to improve their stakeholder relations.

\section{Stakeholder Enabling Through Online Stakeholder Dialogue}

Based on the idea of stakeholder enabling, an ideal has developed for organizations to engage in mutually beneficial dialogues with stakeholders to establish and negotiate social legitimacy (Johansen, Nielsen, 2011; Balser, McClusky, 2005). Organizations engage in dialogue with stakeholders in order to receive feedback with the ultimate goal of both organizations and stakeholders to adapt to the expectations of the other party. Although informing stakeholders through one-way communication may remain important, organizations should try to focus on involving stakeholders in order to foster relationship growth (Morsing, Schultz, 2006).

Kent and Taylor (1998) made a distinction between two-way symmetrical communication 
and dialogic communication. They argued that two-way symmetrical communication is the process whereby an organization and its stakeholders communicate in an interactive way. Dialogic communication can rather be seen as a product of ongoing two-way communication: a type of relational interaction in which a relationship exists (Kent, Taylor, 1998, 2002). Engaging in dialogue changes the relationship between organization and stakeholder as it underlines their equality (Kent, Taylor, 2002). It is therefore regarded as a more ethical form of communication (Theunissen, Noordin, 2012). What distinguishes dialogue from other forms of two-way communication, such as a discussion or debate, is an emphasis on openness, willingness to consider alternative viewpoints, and understanding between parties (Burchell, Cook, 2008). When engaging in true dialogic communication, two or more parties negotiate ideas and opinions by listening to and engaging with each other, incorporating the goal of building common ground (Burchell, Cook, 2008; Kent, Taylor, 1998). Dialogue will therefore lead to greater knowledge and understanding, both integral to relationships (Theunissen, Noordin, 2012).

Because of its distinct characteristics, such as the possibility for real-time interaction and not being bound by space and time, social networking sites are an important platform to engage in dialogue and build relationships (Kent, 2010). Besides communicating directly with publics, social media's strength is that messages are delivered in a format that stimulates engagement leading to relationship growth (Kent, Taylor, 2002; McCorkindale, DiStaso, Sisco, 2013).

\section{Online Dialogic Strategies}

By presenting different online dialogue strategies, Kent and Taylor (1998) paved the way for research investigating the use of online dialogue strategies by organizations (e.g. Kelleher, 2009; Kelleher, Miller, 2006; Waters et al., 2009; Lovejoy, Saxton, 2012; Seltzer, Mitrook, 2007). Four strategies are mentioned routinely within the public relations literature. The first is usefulness of information. Organizations should provide information, which is of value to all stakeholders. This could include information about the organization, its history and mission, how to donate money or become affiliated (Kent, Taylor, 1998; Ingenhoff, Koelling, 2009; Rybalko, Seltzer, 2010). Second, organizations should encourage the conservation of visitors. Stakeholders should be stimulated by the organization to stay on their page rather 
than going to the pages of competitors (Taylor et al., 2001). Organizations can try to stimulate conservation of visitors by linking to other pages owned by the organization (Rybalko, Seltzer, 2010). Furthermore, organizations should stimulate the generation of return visits by implementing features that make it interesting for stakeholders to return to the page. Building relationships with stakeholders takes time and cannot be established in a single visit (Taylor et al., 2001). Encouraging visitors to return can be done by offering updated information, events calendars, or asking stakeholders to return (Taylor et al., 2001). The final and most important aspect of dialogic communication is the dialogic loop implying that the organization and stakeholders send mutual feedback (Kent, Taylor, 1998). Applying a dialogic loop can be defined as whether the organization poses a question to start the dialogue or responds to questions and comments (Rybalko, Seltzer, 2010).

These four dialogic strategies can be divided into two clusters: the technical and design cluster, consisting of the usefulness of information and the conservation of visitors, and the dialogic cluster, consisting of generation of return visits and dialogic loop (Taylor et al., 2001). It is argued that even if an organization follows the first three dialogic strategies, they will never achieve true dialogue until they apply a dialogic loop (Taylor et al., 2001). Interactions in the form of dialogue must take place for relationships to fully thrive as dialogue forms the foundation for successful and ongoing relationships (Taylor et al., 2001; Jo, Kim, 2003). These dialogic strategies have originally been developed to study stakeholder dialogue on corporate websites and the use of these dialogic strategies on websites has often been examined (Ingenhoff, Koelling, 2009; Kent, Taylor, White, 2003; Kent, Taylor, 1998; Taylor et al., 2001; Taylor, Kent, 2004). However, little is known in relation to NPOs usage of these online dialogic strategies on their corporate Facebook page:

RQ1: To what extent do NPOs apply dialogic strategies on their corporate Facebook profile?

Although researchers mentioned the importance of the dialogic aspect, several studies indicate that NPOs use social media to a large extent for informational purposes (Guidry et al., 2014; Park et al., 2016; Huang et al., 2016). The research of Taylor et al. (2001) showed that activist organizations embraced the technical and design aspect of stakeholder relationship building on their websites, while the dialogical aspect of stakeholder relationship building remained underdeveloped. In addition, Ingenhoff and Koelling (2009) studied the websites of Swiss 
NPOs and found that these websites do meet the technical and design aspects for dialogic communication, but also lack the realization of dialogic features. These studies showed that NPOs fall short in applying the dialogical aspect of stakeholder relationships building on their corporate websites. The same might apply to the Facebook pages of NPOs:

H1: NPOs' Facebook pages feature more technical and design aspects compared to dialogic features.

\subsection{Stakeholders' Online Response}

By studying how organizations can initiate stakeholder dialogue and apply strategies to build stakeholder relations online, research has mostly focused on the organizations position within stakeholder dialogue (Ingenhoff, Koelling, 2009; Kent et al., 2003; Kent, Taylor, 1998; Taylor et al., 2001; Taylor, Kent, 2004). Research on stakeholders' online response to organizational relationship-building communication efforts is scarce, even though social networking sites provide scholars with the opportunity to study stakeholders' response objectively in realtime without the interference of any stimulation (Saxton, Waters, 2014). Bortree and Seltzer (2009) showed that organizational engagement in the form of organizational comments in dialogic spaces positively influence dialogic outcomes, such as network activity and growth (Bortree, Seltzer, 2009). However, this study only examined the effect on the Facebook level, without looking at the actual messages organizations send and stakeholders' response to these. Research on the effects of the content of organizational messages found that especially community building messages, promoting interactivity and dialogue, positively influenced stakeholders' response as these messages boosted stakeholders' interest and engagement (Saxton, Waters, 2014). Moreover, Bellucci and Manetti (2017) found a positive tenor in stakeholder comments to NPO posts.

These studies suggest that organizations' focus on initiating stakeholder dialogue can positively influence stakeholders' online response (also see Theunissen, Noordin, 2012; Morsing, Schultz, 2006). Based on the prior arguments it is expected that the communication strategy of a dialogic loop will positively influence stakeholders' response, like stakeholders' interest in the content of the organization's message and stakeholders' engagement with 
the dialogue. Furthermore, it can be assumed that stakeholders will put more effort in the dialogue by providing a more extensive replies. Concluding from this review, the following hypothesis results:

H2: The application of a dialogic loop on NPOs Facebook pages positively influences stakeholders' (a) interest, (b) engagement, and (c) effort.

\subsection{Relational Maintenance Strategies to Build and Maintain Relationships}

When organizations engage with their stakeholders online, they can apply relational maintenance strategies. Based on interpersonal communication literature two relational maintenance strategies have been studied regularly: communicated relational commitment and conversational human voice (Kelleher, 2009). Conversational human voice is used by organizations to connect with their stakeholders on a personal level. This gives stakeholders the feeling of having a conversation with an actual human instead of a lifeless organization (Park, Lee, 2013). Research showed that conversational human voice leads to positive attitudes towards an organization and an increases the intention to engage in positive word of mouth (Yung, Kang, Johnson, 2010). In addition, Kelleher and Miller (2006) showed that this strategy positively influences stakeholders' perception of their relationship with the organization as it increased stakeholders' trust in the organization, satisfaction of the organization and commitment to the organization. Although research on the use of a conversational human voice showed the effectiveness of this strategy, whether this strategy is in practice used by NPOs on social media has yet to be studied:

RQ2: To what extent do NPOs apply the relational maintenance strategy of conversational human voice on their corporate Facebook page?

Based on the presented research showing favorable effects of conversational human voice it is hypothesized that:

H3: The use of a conversational human voice on NPOs Facebook pages positively influences stakeholders' (a) interest, (b) engagement, and (c) effort.

Communicated relational commitment, the second relational maintenance strategy, is used 
by organizations to communicate legitimacy and openness to their stakeholders (Smith, 2010) and can be found in expressions of members of an organization regarding "their commitment to building and maintaining a relationship" (Kelleher, 2009, p. 176). Openness is about openly and freely discussing issues, thoughts and ideas. Assurance is another important feature in the sense that organizations assure their stakeholders that their concerns are legitimate, while also showing they are committed to maintaining the relationships with their stakeholders (Kelleher, 2009; Kelleher, Miller, 2006). Studying the effects of communicated relational commitment in weblogs Kelleher and Miller (2006) found that like the use of this strategy positively affected stakeholders' trust, satisfaction, and commitment (Kelleher, Miller, 2006). However, little is known about how NPOs apply this strategy on their Facebook pages:

RQ3: To what extent do NPOs apply the relational maintenance strategy of communicated relational commitment on their corporate Facebook page?

As research showed the positive influence of the use of communicated relational commitment on stakeholders' perception of their relationship with an organization, it can be assumed that:

H4: The use of communicated relational commitment on NPOs' Facebook pages positively influences stakeholders' (a) interest, (b) engagement, and (c) effort.

\section{Method}

\subsection{Research Design and Sample}

A quantitative content analysis of the Facebook pages of NPOs was conducted with the goal of investigating how these organizations are using dialogic strategies and online relational maintenance strategies. In addition, stakeholders' comments were studied to investigate stakeholders' online response to such organizational relationship-building communication efforts. Facebook was chosen for the analysis as Facebook is globally the most popular social networking site where organizations and stakeholders can communicate as equal partners without any limitations of words (Waters et al., 2009). The program NVivo was used to gather the coding material. 


\subsubsection{Organizations}

For this study, ten NPOs were selected from a list of the top 50 nonprofits on Facebook based on their number of Facebook likes (Top Nonprofits on Facebook, 2014). The following criteria were applied for the selection: Only NPOs with an international character, meaning they are active in multiple countries and had an international corporate Facebook profile page in the English language, were selected. In addition, solely charitable organizations focusing on social or environmental causes were investigated (see Table A1 for an overview).

Table A1. Sample overview

\begin{tabular}{|c|c|c|c|}
\hline NPO & Ranking & Number of posts & Number of comments \\
\hline UNICEF & 1 & 21 & 35 \\
\hline Invisible Children & 4 & 2 & 0 \\
\hline PETA & 5 & 27 & 87 \\
\hline WWF & 10 & 23 & 0 \\
\hline Greenpeace & 13 & 24 & 6 \\
\hline Human Rights Watch & 22 & 26 & 1 \\
\hline Save the Children & 28 & 24 & 12 \\
\hline World Vision & 29 & 30 & 1 \\
\hline ONE & 31 & 19 & 1 \\
\hline Doctors without Borders & 37 & 20 & 1 \\
\hline Total & & 216 & 1,676 \\
\hline
\end{tabular}

\subsubsection{Posts and Comments}

This study focused on corporate, English language Facebook pages. The organizational posts on the Facebook pages within a period of one month, from the March 1 to March 31, 2015 were selected. A timespan of one month prevented overrepresentation of one of the organizations (Herring, 2009). Importantly, for 'none of the selected organizations did any major exceptional events such as organizational crises take place during this period. Only stakeholder dialogue initiated by the organization was analyzed resulting in a sample of 
$N=216$ Facebook posts. Except for one organization (Invisible Children), which had a high ranking but only few posts, the number of post was comparable, ranging from 19 to 30. In addition, the comments of both organization and stakeholders on the organizational posts were studied. Non-English posts and comments and comments that included advertisements were excluded. Due to the large amount of stakeholders' comments on posts $(M=100.87)$, only the first 10 comments per post were studied resulting in a total of $N=1,676$ comments of stakeholders and organizations (Table A1).

\subsection{Measures}

The codebook was divided into three levels of coding units: the Facebook profile page, the posts and the comments. To assess intra-coder reliability, 10 percent of the posts and comments was coded again by the principal researcher. The average Krippendorf's Alpha of this study was .96 ( $S D=.07)$, ranging from .68 to 1.00 and was considered sufficient.

\subsubsection{Dialogic Strategies}

The features of the dialogic strategies were measured as dichotomous variables. Usefulness of information was measured by five items including whether or not the Facebook page had a corporate logo as profile picture, a cover photo related to the work of the NPO, and provided information about the NPOs mission, history, on how to become affiliated or contribute money $(M=.75, S D=.16)$. Conservation of visitors was measured by three items including the presence of links to the website, to other Facebook pages, or to other social media channels of the same NPO $(M=.63, S D=.19)$. Generation of return visits was measured by whether the NPO was active on Facebook, the Facebook page provided an event calendar, or explicitly invited stakeholders to return $(M=.57, S D=.16)$. For the Facebook profile analysis the use of a dialogic loop was measured by whether the NPOs allowed stakeholders to post messages, the NPO explicitly invited stakeholders to reply to posts, and rules of conduct were available. The use of a dialogic loop was additionally measured on the posts and comments level by coding whether or not the organization asked a question or replied to stakeholder comments. The variables from both levels were combined $(M=.50, S D=.18)$. 


\subsubsection{Relational Maintenance Strategies}

The scales of conversational human voice and communicated relational commitment were based on Kelleher and Miller (2006). Both scales consisted of average scores of six dummy variables. Conversational human voice $(M=1.53, S D=1.12)$ included items on whether the organization used personalization of the message, used invitational rhetoric, informal speech, or a sense of humor, admitted a mistake or treats others as human. Communicated relational commitment ( $M=.06, S D=.34$ ) was measured by seven items including the communication of aspects, such as commitment to maintain and desire to continue maintaining or building relationships with stakeholders, general commitment to stakeholders, references to future or long-term commitments, the nature of the organization, and quality of relationships.

\subsubsection{Stakeholders' Online Response}

To measure stakeholders' response to the application of a dialogic loop and relational maintenance strategies within the posts, four measures were used (Saxton, Waters, 2014). The number of likes ( $M=3,700.32, S D=6,298.00)$ indicated the level of stakeholders' interest in the content of organizational post, while the number of comments $(M=100.87, S D=288.91)$ indicated the level of stakeholders' engagement with the content of the organizational post. The number of words ( $M=16.98, S D=17.48)$ used by stakeholders, measured stakeholders' effort in the dialogue by providing an extensive reply.

\section{Results}

\subsection{Dialogic Strategies}

RQ1 addressed the extent to which NPOs applied dialogic strategies on their Facebook profile. With a mean of $75 \%$, the strategy usefulness of information was applied the most. While all ten NPOs portrayed a cover photo related to their work and provided information about their mission, only $50 \%$ provided information on how to become affiliated with the organization. The dialogic loop strategy was applied by $50 \%$ of the organizations by allowing stakeholders to post, inviting stakeholders to reply, or providing rules of conduct. The generation of return visits 
strategy, in contrast, was not applied by the organizations in this study. Taking the strategies together, the organizations attached higher importance to the technical and design cluster $(M=69, S D=14)$ then to the dialogic cluster $(M=53, S D=13), t(9)=-2.632, p=.027$, confirming H1.

Within the posts of the organizations, a dialogic loop consisting of at least one question and reply was applied in only $6 \%$ of all posts, and only by three organizations (PETA: $32 \%$ of all posts, followed by UNICEF: $14 \%$ and Greenpeace: $4 \%$ ). Either a question or reply was applied in 33\% of all posts, (ranging from $0 \%$ for Invisible Children to $67 \%$ for UNICEF). Within $61 \%$ of the posts, the NPOs did not apply a dialogic loop, i.e. neither asked questions nor replied to earlier comments (ranging from $7 \%$ for PETA to $87 \%$ for World Vision). At the comment level, a dialogic loop was applied in $1 \%$ of all comments. In total the NPOs replied to less than $5 \%$ of the stakeholder comments. While with $80 \%$ the majority of organizations in this study replied to the comments of stakeholders, none of the NPOs replied a second time when stakeholders replied to these replies. In sum, the results indicate that dialogic strategies are present, however, true dialogue is rather limited and there is considerable variation across organizations.

\subsubsection{Influence of Dialogic Loop on Stakeholder Response}

The use of a dialogic loop significantly predicted the amount of likes, as the results of a one-way ANOVA demonstrated (Table 1). It should be noted that this relation was moderate (et $\left.a^{2}=.035\right)$. The posts with no question and no replies to comments of stakeholders received the least likes $(M=2,754.60, S D=5,493.74)$, while the posts with a question and with replies from the NPO to stakeholders received the most likes $(M=5,705.62, S D=5,400.05)$. Posts with either a question or replies from the organization received an average of 5,058.93 likes ( $S D=7,460.78$ ). A post-hoc test revealed that only the difference in the amount of likes for posts with no question or replies from the NPO and posts with a question or reply was

significant ( $M_{\text {difference }}=-2304.33, p=.037$ ). H2a was supported: the use of a dialogic loop positively influenced stakeholders' interest.

The influence of the use of a dialogic loop on stakeholders' engagement was also significant (Table 1). Posts with no question and no replies from NPOs received the least comments 
( $M=35.18, S D=53.72$ ), while posts with a question and replies from NPOs received the most comments ( $M=527.23, S D=943.21)$. Posts with either a question or reply scored in between ( $M=143.40, S D=232.46)$. Post-hoc tests showed that all three differences were significant: the amount of comments between posts without question or replies and with either a question or a reply $\left(M_{\text {difference }}=-108.22, p=.017\right)$ or both a question and reply $\left(M_{\text {difference }}=-492.05\right.$, $p<.001$ ) and also posts with a question or a reply and posts with both a question and a reply $\left(M_{\text {difference }}=-383.83, p<.001\right)$. H2b was supported: dialogic loop positively influenced the amount of comments of stakeholders.

Lastly, the influence of a dialogic loop on stakeholders' effort turned out to be insignificant (Table 1). The influence of asking a question and replying to comments on the amount of words was tested separately, however, both the effect of asking a question $(t(194)=-.215, p=.830$ ) and replying to comments $(t(194)=.217, p=.829)$ turned out to be insignificant. Therefore, hypothesis $2 \mathrm{c}$ was rejected: dialogic loop did not influence the extensiveness of the reply of the stakeholder, or stakeholders' effort.

Table 1. Influence of Conversational human voice: One-way ANOVA

\begin{tabular}{|l|l|l|l|l|l|l|}
\hline & Sum of Squares & df & Mean Square & F & $p$ & $\eta 2$ \\
\hline Interest & 302338806 & 2 & 151169403 & 3.915 & .021 & .035 \\
\hline Engagement & 3058669.14 & 2 & 1529334.57 & 21.880 & $<.001$ & .17 \\
\hline Effort & 59259.540 & 2 & 307.044 & .502 & .606 \\
\hline
\end{tabular}

Note. $\mathrm{N}=216$

\subsection{Relational Maintenance Strategies}

Within their posts and comments, organizations scored on average $1.53(S D=1.12)$ on the use of a conversational human voice. A paired samples T-test indicated that the organizations applied a conversational human voice significantly more, $t(215)=17.776, p<.001,95 \% C I[1.100$, 
$1.375]$, in their comments $(M=1.59, S D=.94)$ than in their posts $(M=1.49, S D=1.23)$. Again, considerable variation could be observed. While overall, the conversational human voice was applied in $72 \%$ of posts and comments, this amount ranged from $35 \%$ for Human Rights Watch to $100 \%$ for PETA. Of the conversational human voice, the feature of informal speech was applied within $64.8 \%$ of the posts and comments. However, the feature of admitting a mistake was not applied by the organizations.

The organizations used communicated relational commitment less within their posts and comments than the conversational human voice as they scored an average of .06 ( $S D=.34)$. Fifty percent of the organizations used some of the features of communicated relational commitment, while the other half did not use any of these features. With a maximum of $10 \%$ of posts and comments per organization displaying communicated relational commitment, relatively little variation occurred with regard to this factor between organizations. The organizations mostly applied the feature of commitment to maintaining the relationship, as they applied this feature within $2.5 \%$ of their posts and comments. Both the feature of discussing the nature of the organization and emphasizing the quality of the relationship were never applied.

\subsubsection{Influence of Relational Maintenance Strategies on Stakeholder}

\section{Response}

The use of a conversational human voice had a positive, significant influence on stakeholder engagement, as a linear regression analysis demonstrated (Table 2). The use of a conversational human voice was associated with an increase in the number of stakeholder comments by $44.44 \%$. It is important to note that although this result is significant, the amount of variance in the amount of comments predicted by the use of a conversational human voice is low $\left(R^{2}=.036\right)$. H3b was, therefore, marginally supported: the use of a conversational human voice positively influenced stakeholders' engagement. The use of a conversational human voice did not influence stakeholders' interest or the amount of words used by stakeholders in dialogue. Therefore, $\mathrm{H} 3 \mathrm{a}$ and $\mathrm{H} 3 \mathrm{c}$ were rejected. Finally, linear regression analysis showed that the use of communicated relational commitment had no significant effect on the level of stakeholder interest, engagement and effort (Table 3). Therefore, $\mathrm{H} 4 \mathrm{a}, 4 \mathrm{~b}$, and 4c were rejected. 
Table 2. Regression analyses of conversational human voice on stakeholder response

\begin{tabular}{|l|c|c|c|}
\hline Dependent variable & $\mathrm{b}(\mathrm{SE})$ & $\mathrm{b}^{*}$ & $\mathrm{R}^{2}$ \\
\hline Interest & $468.81(349.26)$ & .091 & .008 \\
\hline Effort & $-1.77(1.03)$ & -.122 & .015 \\
\hline Engagement & $44.44(15.80)$ & $.189^{*}$ & .036 \\
\hline
\end{tabular}

Note. ${ }^{*} \mathrm{p}<.05$

Table 3. Regression analyses of communicated relational commitment on stakeholder response

\begin{tabular}{|l|c|c|c|}
\hline Dependent variable & $\mathbf{b}(\mathrm{SE})$ & $\mathbf{b}^{*}$ & $\mathrm{R}^{2}$ \\
\hline Interest & $-1207.74(1713.76)$ & -.048 & .002 \\
\hline Effort & $-4.36(7.26)$ & -.043 & .002 \\
\hline Engagement & $-57.16(78.61)$ & -.050 & .002 \\
\hline
\end{tabular}

\section{Conclusions and Discussion}

The aim of this study was, first, to examine how NPOs were using dialogic and relational maintenance strategies on their Facebook pages to foster stakeholder relationship growth. Second, the effects of both, dialogic and relational maintenance strategies on different forms of stakeholder involvement were examined. Applying both types of strategies on social media was assumed to strengthen relationships with stakeholders and contribute to social legitimacy (Morsing, Schulz, 2006; Kelleher, Miller, 2006; Ospina et al., 2002).

The results confirmed that the NPOs only marginally focused on applying stakeholder dialogue online (e.g., Lovejoy, Saxton, 2012). In agreement with previous research on NPO websites, we found that NPOs focused more on the technical and design aspect of dialogic strategies than on the dialogic aspect (Taylor et al., 2001; Ingenhoff, Koelling, 2009). The organizations mostly focused on providing useful information, while a dialogic loop was applied by only half of the organizations, meaning that merely half of the organizations explicitly allowed and asked stakeholders to actively participate online by posting messages. Also within their posts and comments, NPOs barely applied a dialogic loop by, for instance, asking questions or replying to stakeholders' comments. Moreover, dialogues between organizations and stakeholders were brief as none of the organizations replied to stakeholders a second time. 
In sum, stakeholder dialogue is taking place but only to a small extent.

Analyzing stakeholder responses revealed that applying a dialogic loop positively influenced stakeholders' interest and engagement. Consistent with previous findings (Saxton, Waters; 2014), the present study confirmed that stakeholder dialogue on social media is important as stakeholders show more interest and feel more engaged. Applying a dialogic loop, however, did not increase stakeholders' effort, measured by the extensiveness of stakeholders' replies. Future research should investigate the concept and measurement of dialogical effort more closely and map conditions under which stakeholders are more likely to put more effort in dialogue with organizations.

In addition to dialogue, we assumed that the organizations would make use of relational maintenance strategies as previous studies showed that these strategies would positively influence stakeholder relationships and stakeholders' supportive behavioral intentions towards an organization (Kelleher, Miller, 2006; Kelleher, 2009). This assumption was only slightly confirmed as the organizations barely applied a conversational human voice, which means that instead of communicating with stakeholders in an engaging and natural style, organizations mostly communicated with stakeholder in a corporate tone of voice. Although personalization of messages and informal speech were present, NPOs barely admitted a mistake, used humor, or asked for feedback. In addition, NPOs barely communicated legitimacy and their commitment to the relationships with stakeholders on Facebook.

The reason why NPOs hardly made use of these strategies may be explained by the finding that these relational maintenance strategies barely influenced stakeholders' online response. While conversational human voice was related to greater stakeholder engagement, the use of communicated relational commitment did not influence stakeholders' online response. Park and Lee (2013) found that applying a conversational human voice on weblogs was more likely to be recognized by stakeholders of for-profit organizations compared to NPOs. This might indicate that if NPOs apply conversational human voice or other relational maintenance strategies, stakeholders may be less likely to perceive this strategy and also less affected by it.

The findings of this study confirm that the NPOs hardly follow the advice of public relations literature, stating that stakeholder dialogue is essential for developing positive stakeholder relations (Ospina et al., 2002; Morsing, Schultz, 2006; Kelleher, Miller, 2006). If NPOs want to 
gain social legitimacy the focus on managing positive stakeholder relations is fundamental (Balser, McClusky, 2005). In addition, literature also stated that especially social networking sites provide organizations with the possibility to easily manage these stakeholder relations and engage with stakeholders (Kent, 2010; McCorkindale et al., 2013). The reason why NPOs follow the advice of public relations scholars only to a small extent may be due to limited time and resources, which do not provide NPOs with the possibility to actively engage with stakeholders online. Another reason could be that NPOs, like other organizations, fear the loss of control when they engage in dialogue with stakeholders (van den Berg, Verhoeven, 2017). However, as social networking sites give organizations the opportunity to monitor what is being said about them and actually join in on the conversation, these platforms rather allow the organization to gain more control. In addition, the perception of control mutuality by stakeholders has been found to increase stakeholder participation (Sisson, 2017). Moreover, active involvement on social media has been found to increase loyalty toward an organization (Park et al., 2016). It is, of course, also important to question to what extent the application of stakeholder dialogue is realistic. It is not reasonable to assume that organizations can engage in dialogue online with each and every stakeholder. In addition, Morsing and Schultz (2006) mention that next to stakeholder dialogue, informing stakeholders remains important. However, little is known in relation to an effective balance between informative and dialogical messages.

\subsection{Practical and Theoretical Implications}

This study contributes by not only analyzing the Facebook profiles of NPOs, but analyzing the content of posts and comments in particular. By doing this, the researchers respond to the call to study social media usage of organization on the message level (Guo, Saxton, 2014; Saxton, Waters, 2014). This study further contributes by investigating to what extent NPOs apply relational maintenance strategies on their Facebook pages. Previous studies have looked at the application of relational maintenance strategies on websites, blogs, and Twitter (Kelleher, 2009; Kelleher, Miller, 2006; Park, Lee, 2013). However, these studies mostly focus on experimental designs. How these strategies are used in practice and how NPOs use these strategies on Facebook specifically has never been studied. Research like this can provide 
new insights as to whether NPOs actually follow the advice of public relations practitioners and apply relational maintenance strategies.

Finally, this study contributes by studying stakeholders' online response on organizational relationship-building communication efforts. Research studying stakeholders' online response is scarce, although this can provide organizations with important feedback on their communication efforts. The aim in this study was to study the effect of a dialogic loop and relational maintenance strategies on stakeholders' online response. The findings did not support strong recommendations to apply relational maintenance strategies, as they did not influence stakeholders' online response. However, as this study shows that a dialogic loop did influence stakeholders' interest and engagement, this strategy is recommended to social media practitioners within NPOs.

\subsection{Limitations and Suggestions for Future Research}

The present study focused on dialogues initiated by the organizations while other studies have also looked at stakeholder initiated dialogue (Cho, De Moya, 2014). In addition, within this study the amount of shares were not included as Saxton and Waters (2014) mentioned that shares are more focused on stakeholder-stakeholder interactions then on stakeholderorganization dialogue. Future research could take a more holistic perspective by also taking these aspects into account. Since the relational maintenance strategies were barely applied, the effect of these strategies on stakeholders' response could have been influenced. Higher scores on the scales of the strategies could have led to different or stronger outcomes. Experimental studies could further examine these relationships.

Although involving stakeholders by engaging in stakeholder dialogue is important, Morsing and Schultz (2006) mention that informing stakeholders should not be forgotten. Research has, indeed, shown that informative messages of NPOs are valued by stakeholders (Saxton, Waters, 2014). Future research should take a closer look at stakeholders' preferences for dialogical online communication from NPOs. What is a good balance between dialogue and providing information? Or under which circumstances are stakeholders willing to comment on posts?

Finally, we focused on ten organizations and found considerable variations in their usage of 
dialogic strategies. Since these were the most popular international NPOs from the charity sector on Facebook, however, insights from this study can be regarded as relevant for other NPOs as well. While the analysis of Facebook conversations over the course of one month has assured comparability across organizations, a longitudinal approach would offer more insights on dynamic aspects of building stakeholder relationships online.

\subsection{Concluding Thoughts}

This study extends the line of research on online stakeholder relations by examining the application of dialogic strategies and relational maintenance strategies on the Facebook pages of internationally active NPOs. Social networking sites offer organizations an important new platform to build stakeholder relations. This study contributes to public relations literature as it investigates NPOs usage of dialogic strategies and relational maintenance strategies on the message level. In addition, this study takes full advantage of the research opportunities of social media as it studies stakeholders' online response to NPOs relationship-building efforts. Future research should continue studying online stakeholder dialogue and stakeholders' preferences of online communication.

\section{Reference List}

- Balser, D., McClusky, J. (2005). Managing stakeholder relationships and nonprofit organization effectiveness. Nonprofit Management and Leadership, 15 (3), 295-315. DOI: 10.1002/nml.70.

- Bellucci, M., Manetti, G. (2017). Facebook as a tool for supporting dialogic accounting? Evidence from large philanthropic foundations in the United States. Accounting, Auditing \& Accountability Journal, 30 (4), 874-905. DOI: 10.1108/AAAJ-07-2015-2122.

- Bortree, D., Seltzer, T. (2009). Dialogic strategies and outcomes: An analysis of environmental advocacy groups' Facebook profiles. Public Relations Review, 35 (3), 317-319. DOI: 10.1016/j.pubrev.2009.05.002.

- Burchell, J., Cook, J. (2008). Stakeholder dialogue and organisational learning: Changing relationships between companies and NGOs. Business Ethics: A European Review, 17 (1), 35-46. DOI: 10.1111/j.1467-8608.2008.00518.

- Cho, M., De Moya, M. (2014). Understanding public s' engagement with non-profit organisations through Facebook: A typology of messages and motivations behind public-initiated conversations. Prism, 11 (2), 1-12.

- Greenleaf, J. (2016). Nonprofit use of social media: Insights from the field. Global Journal of Community Psychology Practice, 7 (3). Retrieved from http://www.gicpp.org/en/article.php?issue=23\&article=141. July, 15, 2017.

- Guidry, J., Waters, R., Saxton, G. D. (2014). Moving social marketing beyond personal change to social change. Strategically using Twitter to mobilize supporters into vocal advocates. Journal of Social Marketing, 4 (3), 240-260. DOI: 10.1108/ISOCM-02-2014-0014.

- Guo, C., Saxton, G. D. (2014). Tweeting social change: How social media are changing nonprofit advocacy. Nonprofit and Voluntary Sector Quarterly, 43 (1), 57-79. DOI: 10.1177/0899764012471585.

- Herring, S. C. (2009). Web content analysis: Expanding the paradigm. In: Hunsinger, J., Klastrup, L., Allen, M. (Eds.), International Handbook of Internet Research (pp. 233-249). Dordrecht: Springer Netherlands. DOI: 10.1007/978-1-4020-9789-8_14.

- Huang, Y. C., Lin, Y. P., Saxton, G. D. (2016). Give me a like: How HIV/AIDS nonprofit organizations can engage their audience 
on Facebook. Aids Education and Prevention, 28 (6), 539-556. DOI: 10.1521/aeap.2016.28.6.539.

- Ingenhoff, D., Koelling, A. M. (2009). The potential of Web sites as a relationship building tool for charitable fundraising NPOs. Public Relations Review, 35, 66-73.

- Jo, S., Kim, Y. (2003). The effect of web characteristics on relationship building. Journal of Public Relations Research, 15 (3), $199-223$.

- Johansen, T., Nielsen, A. (2011). Strategic stakeholder dialogues: a discursive perspective on relationship building. Corporate Communications: An International Journal, 16 (3), 204-217. DOI: 10.1108/13563281111156871.

- Kelleher, T. (2009). Conversational voice, communicated commitment, and public relations outcomes in interactive online communication. Journal of Communication, 59 (1), 172-188. DOI: 10.1111/j.1460-2466.2008.01410.

- Kelleher, T., Miller, B. (2006). Organizational blogs and the human voice: Relational strategies and relational outcomes. Journal of Computer-Mediated Communication, 11 (2), 395-414.

- Kent, M. (2010). Directions in social media for professionals and scholars. In: Heath, R. (Ed.), Handbook of Public Relations (pp. 447-460). New York: Sage.

- Kent, M., Taylor, M. (1998). Building dialogic relationships through the World Wide Web.Public Relations Review, 24 (3), 321 -334.

- Kent, M., Taylor, M. (2002). Toward a dialogic theory of public relations. Public Relations Review, 28 (1), 21-37.

- Kent, M., Taylor, M., White, W. (2003). The relationship between website design and organizational responsiveness to stakeholders. Public Relations Review, 29 (1), 63-77.

- Lovejoy, K., Saxton, G. D. (2012). Information, community and action: How nonprofit organizations use social media. Journal of Computer-Mediated Communication, 17 (3), 337-353.

- McCorkindale, T., DiStaso, M., Sisco, H. (2013). How millennials are engaging and building relationships with organizations on Facebook. The Journal of Social Media in Society, 2 (1), 66-87.

- Morsing, M., Schultz, M. (2006). Corporate social responsibility communication: stakeholder information, response and involvement strategies. Business Ethics: A European Review, 15 (4), 323-338.

- Nah, S., Saxton, G. D. (2012). Modeling the adoption and use of social media by nonprofit organizations. New Media \& Society, $0(0), 1-20$.

- Ospina, S., Diaz, W., O’Sullivan, J. (2002). Negotiating accountability: Managerial lessons from identity-based nonprofit organizations. Nonprofit and Voluntary Sector Quarterly, 31 (1), 5-31.

- Park, H., Lee, H. (2013). Show us you are real: The effect of human-versus- organizational presence on online relationship building through social networking sites. Cyberpsychology, Behavior, and Social Networking, 16 (4), 265-271.

- Park, H., Reber, B. H., Chon, M. G. (2016). Tweeting as health communication: Health organizations' use of Twitter for health promotion and public engagement. Journal of Health Communication, 21 (2), 188-198. DOI: 10.1080/10810730.2015.1058435.

- Park, J., Chung, T. L., Hall-Phillips, A., Anaza, N. A. (2016). Loyalty to social ventures in social media: The role of social cause involvement, identification, and commitment. Journal of Nonprofit \& Public Sector Marketing, 28 (3), 185-208. DOI: 10.1080/10495142.2015.1015378.

- Rybalko, S., Seltzer, T.(2010). Dialogic communication in 140 characters or less: How Fortune 500 companies engage stakeholders using Twitter. Public Relations Review, 36 (4), 336-341.

- Saxton, G. D., Waters, R. (2014). What do stakeholders like on Facebook? Examining public reactions to nonprofit organizations' informational, promotional, and community-building messages. Journal of Public Relations Research, 26 (3), 280 -299.

- Seltzer, T., Mitrook, M. (2007). The dialogic potential of weblogs in relationship building. Public Relations Review, 33 (2), $227-$ 229. DOI: 10.1016/j.pubrev.2007.02.011.

- Sisson, D. C. (2017). Control mutuality, social media, and organization-public relationships: A study of local animal welfare organizations' donors. Public Relations Review, 43 (1), 179-189. DOI: 10.1016/j.pubrev.2016.10.007.

- Smith, B. (2010). Socially distributing public relations: Twitter, Haiti, and interactivity in social media. Public Relations Review, 36 (4), 329-335.

- Taylor, M., Kent, M. (2004). Web sites and their potential for public dialogue. Atlantic Journal of Communication, 12 (2), $59-76$. DOI: $10.1207 / \mathrm{s} 15456889$ ajc1202_1.

- Taylor, M., Kent, M., White, W. (2001). How activist organizations are using the Internet to build relationships. Public Relations Review, 27 (3), 263-284.

- Theunissen, P., Noordin, W. (2012). Revisiting the concept “dialogue” in public relations. Public Relations Review, 38 (1), 5-13.

- Top Nonprofits on Facebook. (2014). Retrieved from: https://topnonprofits.com/lists/top-nonprofits-on-facebook/.April 10, 2015.

- Van den Berg, A., Verhoeven, J. W. M. (2017). Understanding social media governance: Seizing opportunities, staying out of trouble. Corporate Communications: An International Journal, 22 (1), 149-164. DOI: 10.1108/CCIJ-06-2015-0035.

- Waters, R., Burnett, E., Lamm, A., Lucas, J. (2009). Engaging stakeholders through social networking: How nonprofit organizations are using Facebook. Public Relations Review, 35 (2), 102-106.

- Yung, S., Kang, M., Jonhson, P. (2010). Effects of narratives, openness to dialogic communication, and credibility on engagement in crisis communication through organizational blogs. Communication Research, 37 (4), 473-497. 

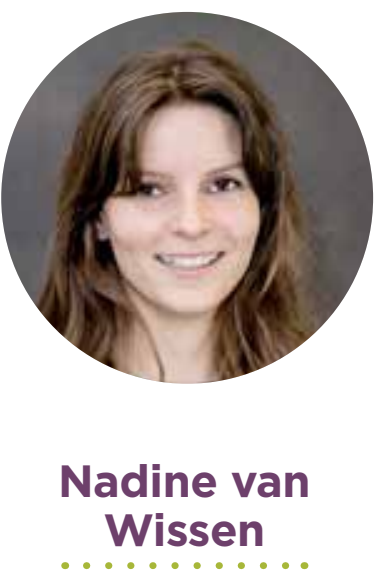

Nadine van Wissen obtained a MSc in Communication Science, track Corporate Communication, at the University of Amsterdam, the Netherlands. With a passion for animal welfare, she currently works as a Junior Online Marketeer at World Animal Protection, the Netherlands. Her current responsibilities include online content creation and activating stakeholders through campaigning. In addition, Nadine works as a content editor at the online community AnimalsToday.nl.

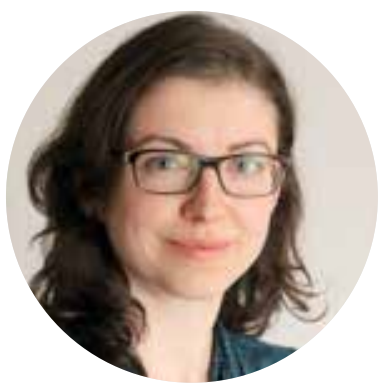

\section{Anke Wonneberger}

Anke Wonneberger received her $\mathrm{PhD}$ from the University of Amsterdam, the Netherlands and held a postdoc position at the University of Vienna, Austria. She is now an assistant professor in Corporate Communication at the Department of Communication Science, University of Amsterdam. Her research topics include strategic communication of non-profit organizations and environmental communication. 